MATEC Web of Conferences 33, 07004 (2015)

DOI: $10.1051 /$ matec conf/ 20153307004

(C) Owned by the authors, published by EDP Sciences, 2015

\title{
Characterization of micro machined surface from TRIP/TWIP steels
}

\author{
M. Smaga ${ }^{1, a}$, T. Beck ${ }^{1}$, P. Arrabiyeh², I. Reichenbach², B. Kirsch², J.C. Aurich² \\ ${ }^{1}$ Institute of Materials Science and Engineering (WKK), University of Kaiserslautern, Germany \\ ${ }^{2}$ Institute for Manufacturing Technology and Production Systems (FBK), University of Kaiserslautern, Germany
}

\begin{abstract}
In this contribution micro machining induced changes in surface morphology, including phase transformation from fcc-austenite into hcp- and bcc-martensite as well as defined surface topography of TRIP/TWIP steel was characterized by scanning electron microscopy using electron backscatter diffraction (EBSD) technique. For this, applying micro milling and micro grinding processes with tool diameter of $45 \mu \mathrm{m}$, structures were machined into flat specimen surfaces of X30MnAl17-1 steel in defined areas previously characterized by EBSD.
\end{abstract}

\section{Introduction}

Surface morphology of metallic materials significantly influences mechanical properties like e.g. fatigue strength [1-3] as well as tribological properties like wear and friction [4-5]. On the one hand, surface morphology can be modified by manufacturing processes [6-8]. On the other hand, significant changes in microstructure and, consequently, variation in mechanical and physical properties can be achieved depending on chemical composition and heat treatment [9-11].

High alloy transformation induced plasticity / twinning induced plasticity (TRIP/TWIP) steels offer microstructural changes by martensitic transformation and twining to achieve outstanding mechanical and tribological properties. Due to alloying with manganese, aluminium and silicium a fully paramagnetic metastable fcc-austenitic microstructure can be achieved at ambient temperature, which transforms by mechanical deformation into paramagnetic hcp-martensite and/or ferromagnetic bcc-martensite as well as forms twins, respectively [9-11]. Because of high metastability of such TRIP/TWIP steels the above mentioned processes can take place at ambient or elevated temperature.

Micro milling and micro grinding are suitable for manufacturing component surfaces with defined morphology on the microscale. Actually the minimal size of structures manufactured by micro milling and micro grinding is $4 \mu \mathrm{m}$ [12-13], of course depending on the material machined. Up to now, micro machining processes were investigated for copper [14-15], AISI 1045 steel [16] and titanium [17], but no results from literature are known for TRIP/TWIP steels. In this contribution, the influences of micro machining process on the surface and near surface morphology of TRIP/TWIP steel are presented and discussed.

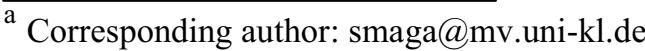

\section{Material and experimental setup}

The investigated $\mathrm{X} 30 \mathrm{MnAl17-1}$ steel was provided as sheet with $1.5 \mathrm{~mm}$ thickness. This TRIP/TWIP steel was developed and manufactured within the CRC 761 "steel ab initio", Aachen, Germany. The nominal chemical composition is given in Tab. 1 .

Table 1. Chemical composition

\begin{tabular}{|c|c|c|c|}
\hline & C & Mn & Al \\
\hline X30MnAl17-1 & 0.3 & 17 & 1 \\
\hline
\end{tabular}

\subsection{Microstructure and mechanical properties}

\subsubsection{Initial microstructure and chemical composition}

The material was delivered in cold-rolled state, with a degree of deformation of $50 \%$ and resulting hardness 437 HV10. The as-delivered microstructure is shown in Fig. 1.

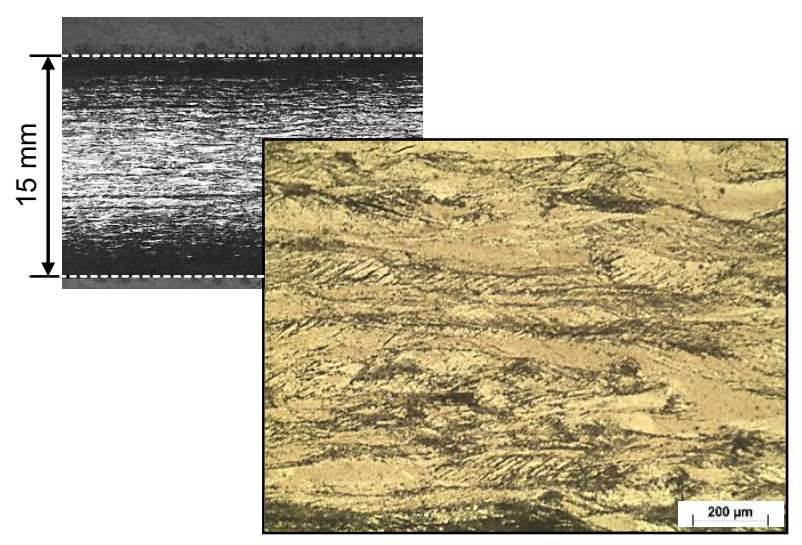

Figure 1. Optical micrograph of as-received state, Klemm etching. 
Due to cold-rolling a characteristic microstructure with grains elongated along the rolling direction, including austenite, martensite as well as twins is formed. Magnetic Feritscope $^{\circledR}$ measurements reveal a homogenous distribution of 17 FE.-\%, which directly correlates with the ferromagnetic $\alpha^{\prime}$-martensite fraction. In literature [18] a linear correlation between Feritscope ${ }^{\circledR}$-unit FE.-\% and $\alpha^{\prime}$-martensite content $\left(\alpha^{\prime}=1.7 \times\right.$ XE. $\left.-\%\right)$ is given for metastable austenitic $\mathrm{Cr}-\mathrm{Ni}$ stainless steels. For TRIP/TWIP steels based on the Fe-Mn-Al-Si concept the relationship between magnetic Feritscope ${ }^{\circledR}$ unit and vol.- $\%$ of $\alpha^{\prime}$-martensite is not quantified yet.

\subsubsection{In situ x-ray investigation of thermal induced martensite - austenite back transformation}

To obtain a fully austenitic microstructure as well as for characterisation of kinetics of thermally induced martensite-austenite back transformation, in situ x-ray phase analysis during heating from ambient temperature up to $1200^{\circ} \mathrm{C}$ was performed using a heat chamber applied in an Empyrean-diffractometer. A 10x10x1.5 mm sized specimen was stepwise $\left(50^{\circ} \mathrm{C} /\right.$ step $)$ heated in vacuum, held for 30 minutes at each step and analyzed using $\mathrm{CuK}_{\alpha}$ radiation with a spot size of $1.5 \times 1.5 \mathrm{~mm}^{2}$. (a)

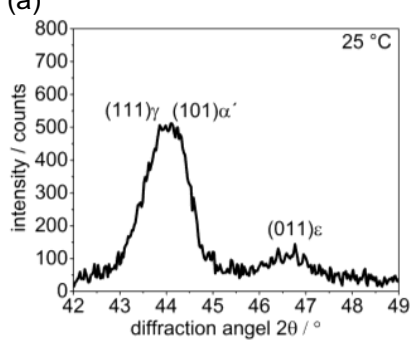

(c)

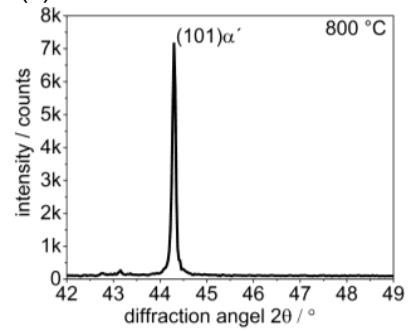

(b)

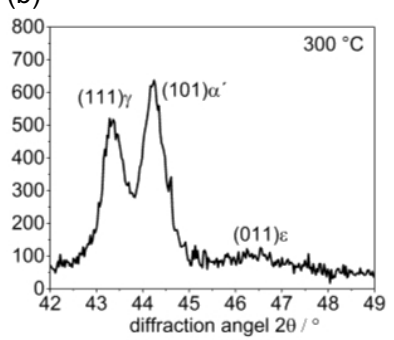

(d)

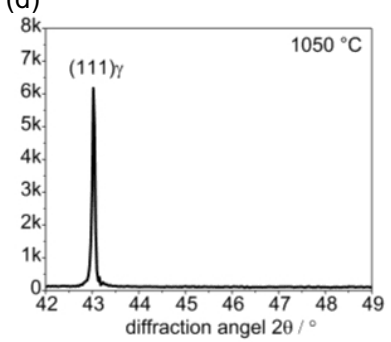

Figure 2. x-ray diffraction maps at $25{ }^{\circ} \mathrm{C}$ (a), $300{ }^{\circ} \mathrm{C}(\mathrm{b})$, $800^{\circ} \mathrm{C}(\mathrm{c})$ and $1050{ }^{\circ} \mathrm{C}(\mathrm{d})$.

Figure 2 shows selected $\mathrm{x}$-ray diffraction maps acquired at $\mathrm{T}=25{ }^{\circ} \mathrm{C}, 300{ }^{\circ} \mathrm{C}, 800{ }^{\circ} \mathrm{C}$ and $1050{ }^{\circ} \mathrm{C}$. In the asdelivered microstructure $\left(\mathrm{T}=25{ }^{\circ} \mathrm{C}\right)$ paramagnetic austenite $(111)_{\gamma}$, ferromagnetic $(101)_{\alpha^{\prime}}$-martensite and paramagnetic $(011)_{\varepsilon}$-martensite are found. Due to high plastic deformation, a significant peak broadening of all three phases is seen. Hence, direct separation of the (111) $\gamma$ from the $(101)_{\alpha^{\prime}}$ peak is not possible in Fig. 2a. However, advanced mathematical methods like Riethveld analysis could enable separation of both phases. At $300{ }^{\circ} \mathrm{C}$ two separate peaks, i.e. $(111)_{\gamma}$ and $(101)_{\alpha^{\prime}}$ can be clearly detected. Further increase of temperature leads to an increase of intensity of $(101)_{\alpha}$-martensite with simultaneous decrease of $(111)_{\gamma}$ and $(011)_{\varepsilon}$-martensite peak intensity. During heating up to $800{ }^{\circ} \mathrm{C}$ the amount of $\alpha^{\prime}$-martensite increased, as previously observed by other authors [19] for metastable austenitic stainless steels. Hence, at $800{ }^{\circ} \mathrm{C}$ only $(101)_{\alpha^{\prime}}$-martensite was measured (Fig. 2c). At temperatures higher than $800{ }^{\circ} \mathrm{C}$ back transformation of martensite into austenite occurs and finally at $1050{ }^{\circ} \mathrm{C}$ no martensite content was measured at all (Fig. 2d). This temperature was therefore used for solution annealing treatment in air for 30 minutes followed by quenching in water bevor the tensile tests described in the next section were started.

\subsubsection{Mechanical properties}

Figure 3 shows stress-elongation and Feritscope ${ }^{\circledR}$-dataelongation curves, measured during a monotonic tensile test at a miniature specimen with a section area of $1.4 \mathrm{~mm}^{2}$ and a gauge length of $10 \mathrm{~mm}$. For the measurement of elastic modulus $\mathrm{E}$ an extensometer with $\pm 10 \%$ strain range was used. Due to the high elongation to fracture of $60 \%$, stress and bcc-martensite fraction are plotted versus elongation, which was measured by the traverse displacement. The tensile test was performed using a Kammrath\&Weiss miniature tensile/compression stage with $\pm 5 \mathrm{kN}$ max. load. The direct relationship between mechanical stress and development of ferromagnetic $\alpha^{\prime}$-martensite is obvious in Fig. 3. This relationship can be used for estimation of stress level in mechanically loaded TRIP/TWIP steels. The mechanical properties are summarized in Table 2.

Table 2. Mechanical properties and hardness of investigated material in solution aneling state $\left(1050{ }^{\circ} \mathrm{C} / 30\right.$ minutes / $\left.\mathrm{H}_{2} \mathrm{O}\right)$.

\begin{tabular}{|c|c|c|c|c|}
\hline $\begin{array}{c}\text { E-Modulus } \\
\text { GPa }\end{array}$ & $\begin{array}{c}\mathbf{R}_{\mathbf{p} 0.2} \\
\text { MPa }\end{array}$ & $\begin{array}{c}\mathbf{R}_{\mathbf{m}} \\
\mathbf{M P a}\end{array}$ & $\begin{array}{c}\mathbf{A} \\
\mathbf{\%}\end{array}$ & $\begin{array}{c}\text { HV 10 } \\
-\end{array}$ \\
\hline 160 & 150 & 605 & 60 & 144 \\
\hline
\end{tabular}

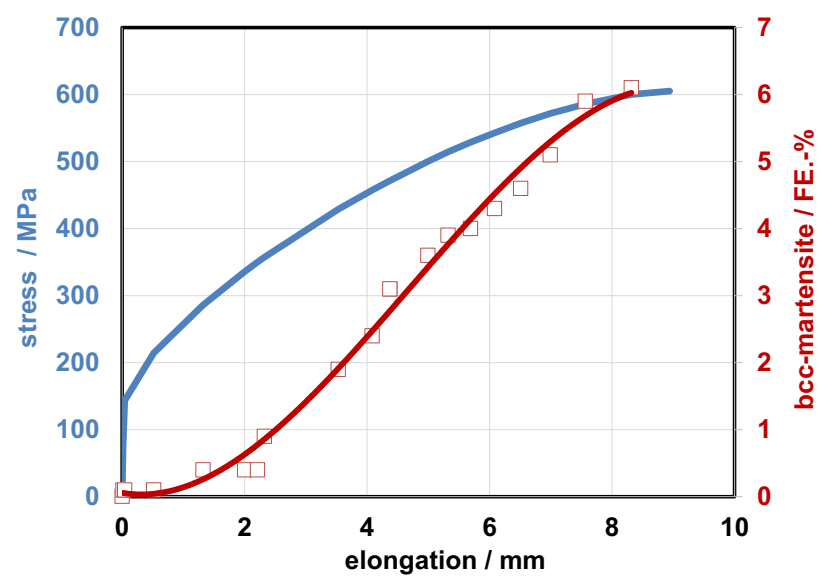

Figure 3. Development of stress and bcc-martensite fraction during monotonic tensile test at ambient temperature 


\subsection{Experimental setup and tools for micromachining}

Parameter studies on machining of TRIP/TWIP steels via micro milling or micro grinding do not exist yet. For the research presented in this paper, parameters were used that were suitable for machining steels with comparable hardness.

\subsubsection{Tool specifications}

The tools to manufacture the micro slots investigated in the present study (a micro end mill and a micro pencil grinding tool (MPGT), depicted in Fig. 4) were manufactured at the Institute for Manufacturing Technology and Production Systems (FBK) of University of Kaiserslautern. The slots were machined on the Nano Grinding Center (NGC), a desktop machine developed at FBK [20].

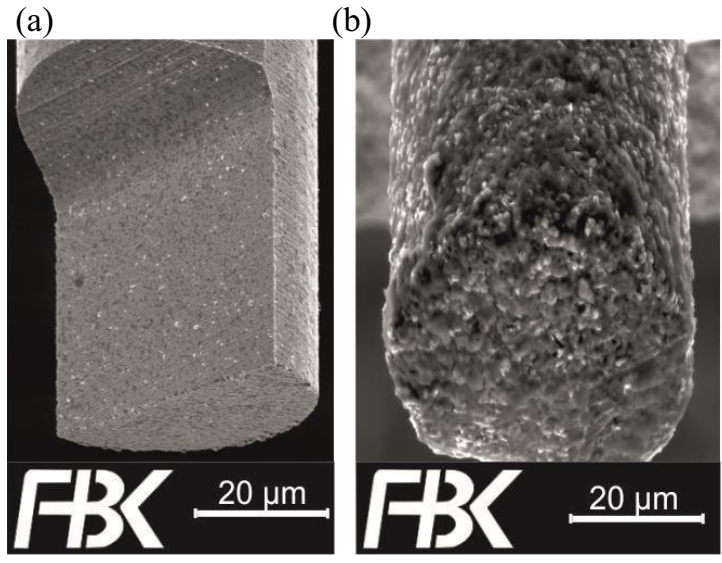

Figure 4. Scanning electron microscope (SEM) pictures of: a $45 \mu \mathrm{m}$ micro end milling tool (a) and a $45 \mu \mathrm{m}$ micro pencil grinding tool (b)

Both tools (blanks) were made of ultra-fine grained cemented carbide (WC in cobalt Matrix) with a hardness of $2000 \mathrm{HV} 30$ [17], a grain size of $0.2 \mu \mathrm{m}, 9 \%$ cobalt and a bending strength of $4800 \mathrm{~N} / \mathrm{mm}^{2}$ [20]. The blanks have a diameter of $1 / 8$ " and a length of $32.5 \mathrm{~mm}$. The geometry of the tools is manufactured using ultra-thin grinding wheels. Details on tool manufacturing can be found in [17] and [20]. The micro end mills provided a rake angle of $0^{\circ}$, a clearance angle of $2.3^{\circ}$ and a minor cutting edge angle of $12^{\circ}$. The MPGT provided electroplated layers with diamond grains. The nominal grain size was D1-D2 (1 to $2 \mu \mathrm{m}$ ), according to the manufacturer of the grains.

\subsubsection{Process design}

For milling, a feed rate of the workpiece $\mathrm{v}_{\mathrm{f}}$ of $15 \mathrm{~mm} / \mathrm{min}$ at a rotational speed of $60000 \mathrm{rpm}$ was used, corresponding to a feed per tooth of $0.25 \mu \mathrm{m}$. For grinding, a feed rate of the workpiece $\mathrm{v}_{\mathrm{f}}$ of $0.1 \mathrm{~mm} / \mathrm{min}$ at a rotational speed of $60000 \mathrm{rpm}$ was used. Both processes are promising techniques to manufacture microscopic structures in a large variety of materials with sufficient material removal rates. The slots were machined on the
NGC. The specimens were clamped onto an application module, a conventional linear $\mathrm{X}-\mathrm{Y}$ stage with an accuracy of $\pm 250 \mathrm{~nm}$ and a unidirectional repeatability of $\pm 25 \mathrm{~nm}$ [20]. The main spindle in which the tools are clamped for manufacturing of the slots features air bearing and is capable of rotational speeds up to 160000 $\mathrm{rpm}$. A camera module with a magnification of 400 at a working distance of $81 \mathrm{~mm}$ is used for process control [20]. The tools are moved towards the specimen in $0.5 \mu \mathrm{m}$ steps until a tool-specimen contact is detected via the camera. This position is used as reference for setting the depth of cut.

\section{Micro machined surfaces}

Eight slots were micro machined at the surface of a flat specimen in fully austenitic state. Four by micro grinding $(\# 1, \# 2, \# 3, \# 4$ in Fig. $5 b)$ and four $(\# 5, \# 6, \# 7, \# 8$ in Fig. $5 \mathrm{~b}$ ) by micro milling, to investigate the influence of both processes on local microstructure, i.e. martensite transformation and twinning. The flat specimen was the same as for in situ x-ray investigations described in section 2.1.2.

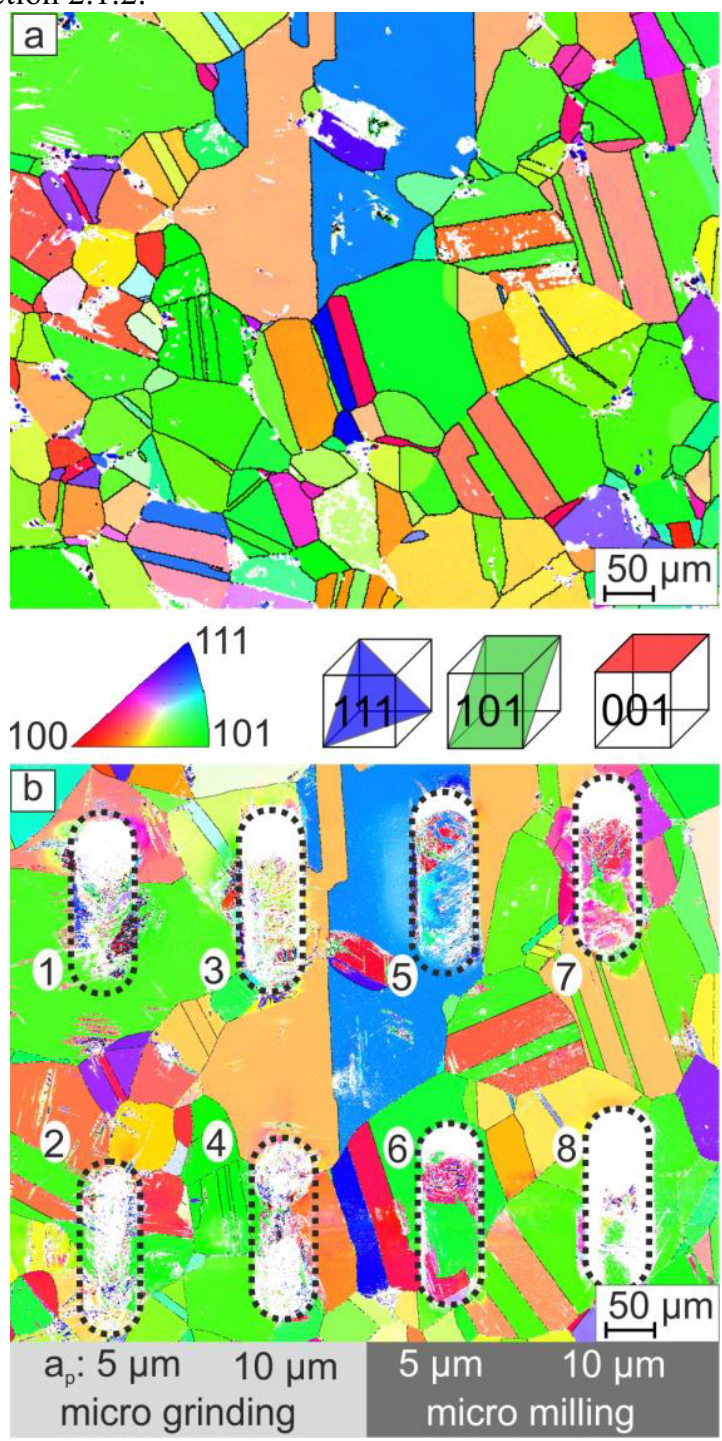

Figure 5. EBSD mappings of grain orientation before (a) and after micro machining (b). 
Each slot provides a length of $150 \mu \mathrm{m}$ and a width of $45 \mu \mathrm{m}$ (corresponding to the diameter of the tools), while the depth $\left(a_{p}\right)$ was varied from 5 to $10 \mu \mathrm{m}$. Each slot was machined in one cut, i.e. the depth of cut was set according to the depth of the slot to be achieved. For characterization of the influence of micro machining an area of $500 \times 500 \mu \mathrm{m}^{2}$ was selected and EBSDcharacterized in its initial state (Fig. 5a). Exactly in this area, marked by micro hardness indents, the eight slots were micro machined according to the parameters given above. An EBSD mapping of the machined area is shown in Fig. 5b. Some slots are localized in multiple grains e.g. slot \#3, others in single (111) $\gamma$ grains, as slot \#5.

\subsection{Micro grinding}

For comprehensive characterization of influences of micro grinding on surface morphology some details of slot \#3, i.e. the initial microstructure (Fig. 6a), topography after micro grinding (Fig. 6b), topography after mechanical and electrolytic polishing (Fig. 6c), grain orientation (Fig. 6d), phase content (Fig. 6e) and miss-orientation (Fig. 6f) after micro machining are shown.
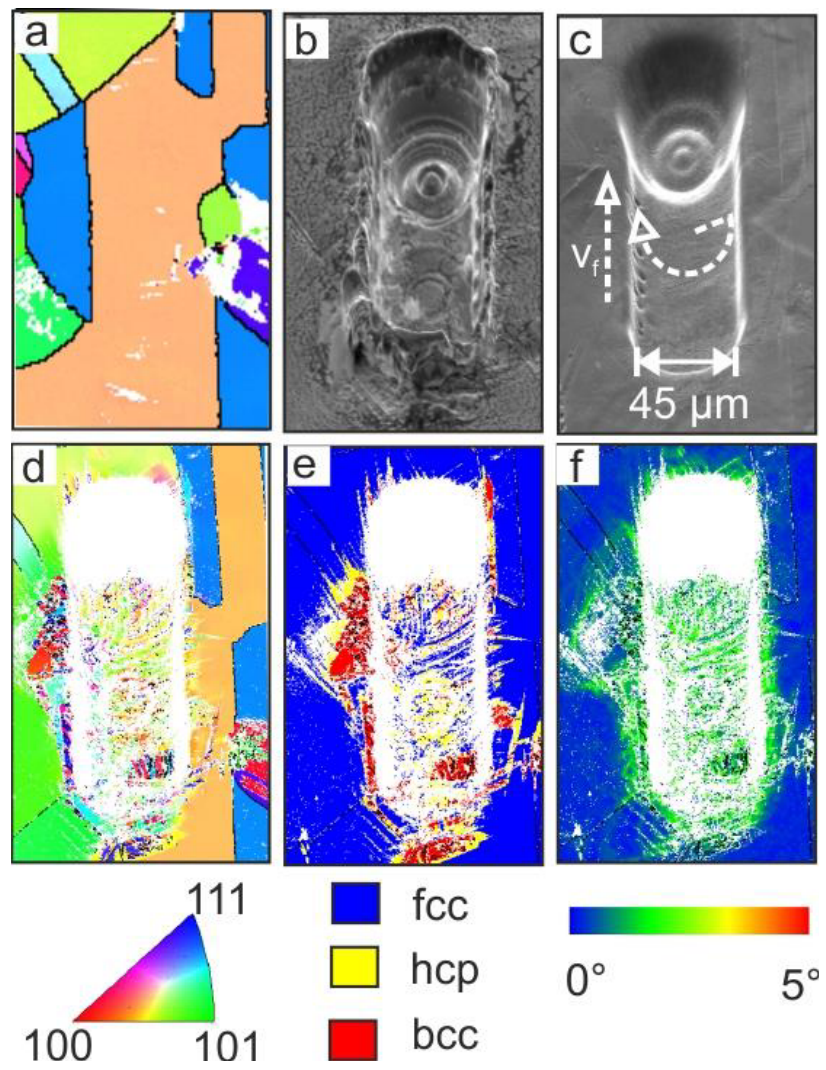

Figure 6. Details of slot \#3; (a) EBSD mapping of initial grain orientations, (b) surface topography after micro grinding, (c) surface after preparation for EBSD investigations, (d) EBSD grain orientations mapping after micro grinding (e) EBSD phase analysis, blue: fcc-austenite / yellow: hcp-martensite / red: bccmartensite, (f) EBSD miss-orientation.

The geometry of slot \#3 is: length $150 \mu \mathrm{m}$, width $45 \mu \mathrm{m}$ (corresponding to the diameter of the tool) and depth $10 \mu \mathrm{m}$. Comparing Fig. 6a with $6 \mathrm{~d}$, the micro grinding induced change in grain orientation can be clearly seen. In the $(101)_{\gamma}$ austenite grain plastic deformation induced phase transformation (comp. 6d and 6e). Hence, higher contents of bcc-martensite and of hcp-martensite were detected in the middle and at the lower end of the slot, while at upper end where the tool was "immersed" into the surface at the beginning of the micro grinding process, could be characterized by EBSD, even after additional polishing, see Fig. 6d. Note that due to the additional polishing step after micro machining (Fig. 6c) material is removed from the surface and, consequently, the observed microstructure around the groove is localized below the initial surface. An increased degree of miss-orientation, which is correlated with higher defect density, was detected inside the slot as well as in the surface regions surrounding the edge.

\subsection{Micro milling}

Figure 7 shows in analogy to Fig. 6 details of microstructure for micro milling of slot \#5 with a length of $150 \mu \mathrm{m}$, a width of $45 \mu \mathrm{m}$ (corresponding to the diameter of the tool) and a depth $5 \mu \mathrm{m}$.
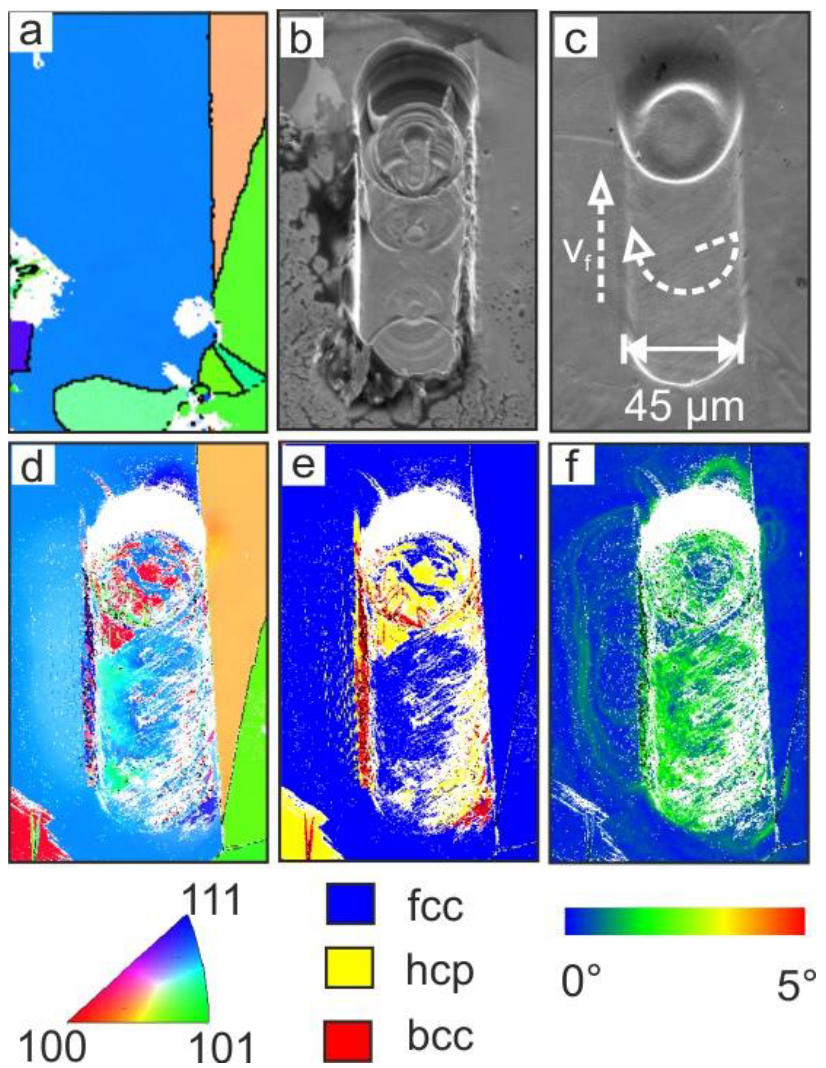

Figure 7. Details of slot \#5; (a) EBSD mapping of initial grain orientations, (b) surface topography after micro grinding, (c) surface after preparation for EBSD investigations, (d) EBSD grain orientations mapping after micro grinding (e) EBSD phase analysis, blue: fcc-austenite / yellow: hcp-martensite / red: bccmartensite, (f) EBSD miss-orientation.

By micro milling it was possible to machine slot \#5 into only one austenite grain with $(111)_{\gamma}$ orientation and the grain boundary along the right edge of the slot (comp. Fig. 7a with Fig. 7d). After careful mechanical and 
electrical polishing, EBSD analysis was, opposed to the micro grinded slot \#3, even possible in the area where the micro milling tool was placed into the material. Note that with a depth of $5 \mu \mathrm{m}$, this slot was two-times flatter than in case of micro grinding. The phase analysis shows higher content of hcp-martensite with small bccmartensite fraction in the region of inlet of micro milling tool at the upper end of the slot. The crystallographic orientation of fcc-austenite and micro milling induced hcp-martensite was $(111)_{\gamma} / /(100)_{\varepsilon}$. Only small amount of bcc-martensite was detected inside the slot, but a higher content of this phase was measured on the down milling side of the tool on the left side of the groove (Fig. 7e). Because a grain boundary is exactly located on the up milling side, further conclusions of influences of milling process (influence of down or up milling) on microstructural changes and phase transformation in a single grain can't be drawn from this specific measurement. However, it should be noted that no transformation is detected in the directly neighbouring grain, indicating that grain boundaries may act as obstacles against phase transformation processes induced by localized plastic deformation. The miss-orientation map (Fig. 7f) shows a higher concentration of plastic deformation/defects at the milling tool insertion area as well as in $(111)_{\gamma}$ austenite grain on the down milling side. Opposite to this, at the up milling side, no significant miss-orientation was measured in the neighbouring grain, which is in-line to the observation that in this region no phase transformation occurred.

\section{Conclusions}

In the present study micro grinding and micro milling were for the first time successfully used for machining the surface of novel, high alloyed, fully austenitic TRIP/TWIP steel based on the Fe-Mn-Al-Si concept, which was developed within the CRC 761 "steel ab initio". The material shows high metastability and, consequently, plasticity induced martensitic phase transformations occur, when plastic deformation takes places during micro machining at ambient temperature. Micro cutting tools with a diameter of $45 \mu \mathrm{m}$ were used both for micro milling and micro grinding. This small tool dimensions allow manufacturing of slots within one grain of the investigated material. Using EBSD, local microstructural changes in the machined slots and at the surrounding surface were characterized. Besides phase transformation from fcc-austenite into hcp- and bccmartensite increased local miss-orientation resulting from the machining processes was identified.

As a mid- to long-term perspective, local phase transformation in TRIP/TWIP steels can be used for the determination of cutting forces during micro machining via inverse problem solving. Determination of force is of special interest for the dimensions presented in this study due to the low magnitudes of force in this regime. Furthermore, micro machined surface from TRIP/TWIP steels can be used for the increase of fatigue and wear resistance by introduction of high strength phases in and close to the machined structures. Both challenges require further systematic experimental and modelling investigations.

\section{References}

1. F. Hahnenberger, M. Smaga, D. Eifler, Int. J. Fat. 69 (2014)

2. M. Smaga, F. Walther, D. Eifler, Mat. Sci. Eng. A 483-484 (2008)

3. M. Bayerlein, H.J. Christ, H. Mughrabi, Mat. Sci. Eng. A 114 (1989)

4. X. Xu, W. Xu, F.H. Ederveen, S. van der Zwaag, 301 Wear (2013)

5. D. Frölich, B. Magyar, B. Sauer, P. Mayer, B. Kirsch, J.C. Aurich, R. Skorupski, M. Smaga, T. Beck, D. Eifler, 328-329 Wear (2015)

6. I. Nikitin, B. Scholtes, Journal of Heat Treatment and Materials 3 (2012)

7. E. Brinksmeier, M. Garbrecht, D. Meyer, CIRP Annals - Manufacturing Technology 57/1 (2008)

8. J.C. Aurich, P. Mayer, B. Kirsch, D. Eifler, M. Smaga, R. Skorupski, CIRP Annals - Manufacturing Technology 63/1 (2014)

9. O. Grässel, L. Krüger, G. Frommeyer, International Journal of Plasticity 16 (2000)

10. H. Springer, D. Raabe, Acta Metall. 60 (2012)

11. W. Song, T. Ingendahl, W. Bleck, Acta Metall. (2014)

12. K. Egashira, S. Hosono, S. Takemoto, Y. Masao, Precision Engineering 35 (2011)

13. J.C. Aurich, M. Carrella, M. Walk, CIRP Annals Manufacturing Technology 64 (2015)

14. M. Zhou, B. K. A. Ngoi, Z. W. Zhong, X. J. Wang, Materials and manufacturing processes (2001)

15. X. Wu, L. Li, N. He, M. Zhao, Z. Zhan, Int J Adv Manuf Technol (2015)

16. A. Simoneau, E. Ng, M.A. Elbestawi, Annals of the CIRP 56/1 (2007)

17. J.C. Aurich, I.G. Reichenbach, G. Schueler, CIRP Annals - Manufacturing Technology 61 (2012)

18. J. Talonen, P. Aspegren, H. Hänninen, Material Science and Technology, 20 (2004)

19. S.S.M. Tavaresa, D. Fruchart, S. Miraglia, Journal of Alloys and Compounds 307 (2000)

20. M. Walk, J.C. Aurich. Procedia CIRP 14 (2014)

\section{Acknowledgments}

The authors thank the German Research Foundation (DFG) for the financial support within the CRC 926 "Microscale Morphology of Component Surfaces". The investigated TRIP/TWIP steel was developed and manufactured within the CRC 761 "steel ab initio" at Department of Ferrous Metallurgy (IEHK), RWTH Aachen University, Germany. We thank Prof. Bleck and his co-workers for their support. 
